\title{
Utilização de perfis básicos e imagens acústicas de poço na caracterização de reserva- tório carbonático da Bacia de Campos
}

Renan de Lima \& Abel Carrasquilla, UENF, Macaé - RJ, Brasil

Copyright 2016, SBGf - Sociedade Brasileira de Geofísica

Este texto foi preparado para a apresentação no VII Simpósio Brasileiro de Geofísica Ouro Preto, 25 a 27 de outubro de 2016. Seu conteúdo foi revisado pelo Comitê Técnico do VII SimBGf, mas não necessariamente representa a opinião da SBGf ou de seus associados. É proibida a reprodução total ou parcial deste material para propósitos comerciais sem prévia autorização da SBGf.

\section{Resumo}

No estudo de reservatórios carbonáticos, uma ferramenta de grande utilidade nesse objetivo são os perfis básicos de poços e perfis especiais como o fotoelétrico e o acústico de imagens. Neste sentido, o presente trabalho tem como principal objetivo utilizar conjuntamente esses perfis na caracterização de um reservatório carbonático da Bacia de Campos, utilizando dados reais da camada pós-sal dessa bacia. O uso conjunto desse conjunto de dados mostrou-se eficaz na caracterização desse reservatório, pois a partir das propriedades petrofísicas derivadas e das imagens geradas o reservatório foi zoneado, os fluidos identificados e diversas estruturas geológicas detetadas, tais como contatos litológicos, inclinação e orientação dos acamamentos, fraturas de origem natural e induzidas pela perfuração, além da caracterização de zonas com porosidade vugular.

\section{Introdução}

As rochas carbonáticas são formadas em ambientes sedimentares com diferentes formas deposicionais que podem ter uma grande variabilidade no número de camadas e estruturas sedimentares. Sua configuração descreve a combinação de processos biológicos, físicos e químicos associados com a deposição de um tipo particular de sedimentos que, futuramente, determinará o tipo de rocha que será formado após a litificação. Os reservatórios carbonáticos estudados neste trabalho estão representados por estruturas isoladas, correspondentes a depósitos de plataforma rasa (Figura 1) que foram formados em ambiente marinho durante o Albiano Inferior/Médio (Torrez et al., 2012). Esse pacote sedimentar, conhecido como Grupo Macaé, é composto pelas formações Quissamã (estratos de dolomitos que são mais delgados nas bordas da bacia), Outeiro (calcilutitos e margas conglomeradas) e Imbetiba (margas com ocorrências de turbidíticos).

Uma forma adequada, com bom custo/benefício, de coletar informações semelhantes as encontradas em um testemunho é através da perfilagem, operação que tem por objetivo obter as propriedades petrofísicas das camadas, sem necessidade de amostrá-las, durante e/ou após a perfuração dos poços (Serra et al., 2004). Entre esses perfis, os de imagens fornecem imagens de alta resolução das formações presentes na parede do poço, sendo a interpretação na maioria das vezes qualitativa.
São imagens que tem como base as características propriedades resistivas, acústicas, densidade, etc. das formações geológicas. As imagens têm um papel importante na descrição do reservatório uma vez que proporcionam informações detalhadas sobre as rochas reservatório, com intervalos de amostragem de cerca de $2.5 \mathrm{~mm}$, enquanto os perfis tradicionais são amostrados a cada 15 $\mathrm{cm}$ Nesse contexto, os perfis acústicos se apresentam como uma alternativa às ferramentas de imagens microrresistivas, especialmente em ambientes de lama à base de óleo, onde estas ferramentas não podem ser corridas, sendo amplamente utilizados na indústria do petróleo, uma vez que também fornecem imagens de toda a circunferência do poço. (Rider \& Kennedy, 2011).

Desta forma, este estudo se propõe usar perfis de poço básicos e especiais (fotoelétrico e de imagens acústicas) de poço para uma melhor caracterização de reservatórios carbonáticos, utilizando dados da camada pós-sal da Bacia de Campos. De forma específica, pretende-se identificar diversas estruturas geológicas presentes na parede do poço, tais como: fraturas e falhas caracterizando as quanto a sua origem, tamanho e direção, contexto deposicional durante a formação da rocha através do acamamento sedimentar, inclinação de camadas e reconhecimento dos contrastes litológicos, desmoronamentos, discordâncias, identificação de camadas delgadas, zonas com porosidade vugular, cavernas, etc.

\section{Metodologia}

Os perfis básicos de poço utilizados neste trabalho foram densidade $(\mathrm{RHOB})$, raios gama $(\mathrm{GR})$, porosidade neutrônica (NPHI) e resistividade (RLA), quanto que os perfis especiais foram o perfil fator fotoelétrico (PEF) e o de imagens acústicas (amplitude e tempo de trânsito). Para carregar e interpretar todos esses perfis foi utilizado o software comercial Interactive Petrophysics (IP), produzido pela LR Senergy (2015). A primeira etapa do trabalho consistiu no uso dos perfis básicos para determinação dos tipos de litologia e fluidos existentes no trecho analisado, o que permite definir as zonas potencialmente acumuladoras de hidrocarbonetos.

A seguir, as imagens acústicas foram usadas para um estudo mais detalhado do poço. Iniciou-se então o processamento dos dados com uma correção ambiental dos dados. Após isso, foram utilizados filtros para refinar os dados, proporcionando imagens mais nítidas, o que torna possível destacar as estruturas horizontais (acamamentos) ou verticais (possíveis fraturas).

Após esse processamento se inicia a interpretação, executada para identificar sinais característicos de determi- 
nadas feições nas imagens bidimensionais. Fraturas abertas, por exemplo, aparecem nas imagens como senoides com diferentes amplitudes e são caracterizadas por se apresentarem com coloração escura, que representam feições com baixa reflexão das ondas acústicas (Luthi, 2003). As discordâncias são caracterizadas por mudança ou interrupção brusca de contraste em determinado intervalo, possibilitando inclusive a caracterização e identificação das diferentes litologias (Crain, 2015).

Algumas feições não-geológicas podem se apresentar nas imagens, sendo conhecidas como image artefacts, as quais não são naturalmente presentes nas formações e sim resultado das operações de perfuração e perfilagem. Essas feições podem ocultar informações importantes e sua identificação deve ser parte do controle de qualidade das imagens, sendo o primeiro passo para interpretação dos perfis. Esse processo deve ser mantido durante todo o estudo pois possibilita detectar estruturas geológicas importantes na caracterização das formações (Lovell et al., 1999).

\section{Resultados}

Os valores GR>100 $\mathrm{API}$ da pista 5 da Figura 2 sugerem a existência de duas zonas no campo estudado: Zona I (0-57 m), que é uma intercalação de camadas argilosas com carbonatos de granulação fina (mudstones). É constituída de uma rocha selante que capea o reservatório existente abaixo e que apresenta baixa porosidade/permeabilidade. A Zona II (57-481 m) é uma extensa sucessão de rochas carbonáticas, com valores de $20<\mathrm{GR}<35^{\circ} \mathrm{API}$. Esta zona é dividida em duas diferentes partes utilizando as curvas RHOB (pista 5) e PEF (pista $6)$ : Zona IIA (57-298 m), com NPHI $=20 \%, R H O B=2.4$ $\mathrm{gr} / \mathrm{cm}^{3}$ e $\mathrm{PEF}=3 \mathrm{~B} / \mathrm{e}$, valores típicos rochas calcárias. A Zona IIB (298-521 m) apresenta NPHI=15\%, RHOB=2.7 $\mathrm{gr} / \mathrm{cm}^{3}$ e $\mathrm{PEF}=5 \mathrm{~B} / \mathrm{e}$, evidenciando a presença de dolomitos. Quando se plota NPHI contra RHOB, nota-se que a Zona IIA aparece nos pontos cinza da Figura 3 (esquerda) sobre a linha LS (calcário) e a Zona IIB aparece em pontos laranja sobre a linha DOL (dolomita). Utilizando os perfis RHOB, NPHI e PEF foi calculado a absorção fotoelétrica da matriz $(U)$, a qual foi plotada contra $\mathrm{RHOB}$ na Figura 3 (direita), notando-se que os pontos referentes às Zonas IIA e IIB aparecem nos vértices de um triângulo referentes ao calcário e dolomito, respectivamente. Nessa mesma figura, a presença do óleo é observada nos altos valores dos perfis resistividade (pista 8) e nos valores baixos da saturação de água (pista 9).

A Figura 4 exibe as imagens obtidas para as amplitudes e tempo de trânsito, tanto no modo estático (imagens à esquerda) quanto dinâmico (imagens à direita), separação que favorece a identificação de contrastes, nos 481 $\mathrm{m}$ analisados. A Zona IIA é representada por uma coloração mais escura (baixa amplitude) por ser mais porosa e atenuar as ondas sonoras. As Zonas I e IIB são representadas por uma coloração mais clara (alta amplitude), por serem relativamente mais densas, e, portanto, refletirem com maior eficiência as ondas sonoras. Na orientação de $300^{\circ} \mathrm{N}$, detectou-se uma faixa vertical mais escura ao longo de todo o poço, que fica mais evidente a partir dos $240 \mathrm{~m}$. Pelo fato de ter sofrido um atrito pela coluna de perfuração, a parede do poço acaba sendo marcada e levemente danificada, o que provoca os tons escurecidos nas imagens de amplitude.

A Figura 5 destaca a Zona I, rocha capeadora do reservatório, observando-se listras horizontais com tons mais escuros e claros de folhelho intercalado com carbonatos finos. O contraste litológico entre as Zonas I e IIA aparece marcado na figura aos $57 \mathrm{~m}$. A Figura 6 mostra uma porção da Zona IIA (acima) e da Zona IIB (abaixo). Nas duas zonas identificaram-se acamamentos quase horizontais com inclinações de $10^{\circ} \mathrm{e}$ em alguns pontos mais pronunciados com aproximadamente $30^{\circ}$. No estereograma da Figura 7, os pontos quadrangulares azuis representam os acamamentos, enquanto que a circunferência azul mostra a orientação real do Poco X no trecho. A partir da distribuição destes pontos constata-se que a maior parte dos acamamentos apresenta mergulho entre $10^{\circ}$ e $50^{\circ}$ na direção $68 \mathrm{SW}\left(220^{\circ} \mathrm{N}\right)$.

Fraturas naturais foram detectadas entre $148-175$ e entre 469-474 m na Figura 8, todas preenchidas por um cimento denso, fazendo com que não contribuam para o incremento da permeabilidade do reservatório. O gráfico estereográfico da Figura 9 indica que os dois grupos de fraturas detectados apresentam direções de mergulhos. O primeiro grupo tem mergulho oposto diferentes (triângulos amarelos) e o segundo de maneira semelhante aos acamamentos (quadrados azuis), enquanto que a circunferência azul mostra a orientação real do Poco $X$ no trecho. Isto sugere que condições de tensão diferentes ocorrem ao longo do poço, provavelmente por causa da zona cimentada.

Heterogeneidades na forma vugs são identificadas nas imagens em 6 zonas do reservatório marcadas entre 354$408 \mathrm{~m}$ com extensão entre um a quatro $\mathrm{m}$ de altura. A Figura 10 exibe duas destas zonas, que apesar de não causarem grandes alterações na curva NPHI. Trata-se de porosidades intra e intergranular que envolvem a dissolução do cimento durante a diagênese, assim como no processo de dolomitização no intervalo de litologia dolomítica.

Artefatos não-geológicos na forma de breakouts aparecem aos $111 \mathrm{~m}$ da Figura 11 na forma de manchas escuras, que indicam um desmoronamento do poço que provoca perda na amplitude sonora. Uma inconformidade geológica neste trecho do poço pode ter provocado essa instabilidade. Nas imagens da Figura 12 são encontrados stuck zones provocados pelos equipamentos quando a coluna de perfuração fica aprisionada no poço, mostrando imagens escurecidas e esticadas que não foram identificadas como anomalias nos outros perfis. Entre 78-90 $m$ da Figura 13, traços escurecidos e bem definidos foram observados a $180^{\circ}$ dos keyseats que existem ao longo de todo o poço.

\section{Conclusões}


Neste trabalho, com o uso dos perfis básicos foi possível identificar as litologias e delimitar o reservatório. O reservatório atravessado pelo Poço $X$ apresentou 400 metros de rochas carbonáticas, sendo 150 metros deste total classificados como possíveis produtores de petróleo. A partir destas informações, foi possível estimar o volume de óleo estocado por estas rochas, delimitando-se a extensão horizontal do reservatório. A partir de imagens acústicas foram detectados contatos litológicos, determinadas a inclinação e orientação dos acamamentos, identificadas fraturas de origem natural e induzidas pela perfuração, estimadas as tensões em determinadas zonas, além da caracterização de zonas com porosidade vugular, o que leva a constatar que se trata de um reservatório bastante heterogêneo. Foram identificadas duas subzonas principais (Zonas IIA e IIB) compostas por calcário e dolomito respectivamente. No entanto, diversos acamamentos, zonas cimentadas e estratos argilosos foram observados em alguns pontos de sua extensão. A presença de zonas com alta ocorrência de vugs confirma ainda mais esta heterogeneidade, tornando a estimativa da porosidade e permeabilidade ao longo do reservatório mais complicada, visto que este tipo de porosidade não apresenta um padrão constante em sua distribuição. Pôde-se perceber que o trecho analisado não apresentou alta incidência de fraturas naturais. Os grupos de fraturas identificados se apresentaram com baixa frequência e preenchidos, não contribuindo para melhorar a permeabilidade da formação, evidenciando que se trata de um reservatório carbonático não fraturado. Verificou-se que as imagens acústicas de amplitude foram muito mais eficientes do que as imagens de tempo de trânsito, o que significa que todas as informações obtidas neste trabalho poderiam ter sido verificadas utilizando-se apenas esse tipo de imagens. Da mesma forma, as diferenças notadas entre as imagens estáticas e dinâmicas facilitaram a detecção e interpretação de alguns contatos horizontais pelas imagens dinâmicas.

\section{Agradecimentos}

Os autores gostariam de agradecer à UOBC - Petrobras pela sua cooperação no fornecimento de dados para publicar este trabalho.

\section{Referências}

Bruhn C., Gomes J., Lucchese C. \& Johann P. 2003. Campos basin: reservoir characterization and management - Historical overview and future challenges. Offshore Technology Conference, Houston, Texas, paper OTC 15220, $14 \mathrm{p}$.

Crain, E. 2015. Crain's Petrophysical Handbook. Online version (https://www.spec2000.net/01-index.htm).

Lovell, M., Williamson, G. \& Harvey, P.1999. Borehole imaging: applications and case histories, Geological Society special publication, no. 159. Geological Society, London, p. $1-43$.

LR Senergy. 2014. Interactive Petrophysics v4.3, Online user's manual (http://www.Ir-senergy.com/software/ip).
Luthi, S. 2001. Geological well logs: their use in reservoir modeling. Springer-Verlag, Berlin, $373 \mathrm{p}$.

Rider, M. \& Kennedy, M. 2011. The geological interpretation of well logs. Rider-French Consulting Limited, Sutherland, UK, $440 \mathrm{p}$.

Serra, O. \& Serra, L. 2004. Well logging and geology. Serralog, Calvados, France, $436 \mathrm{p}$.

Torrez, M., Barreto, E., Carrasquilla, A. \& Sanchez, P. 2012. Incorporating texture and pore size distribution in electrofacies modeling to improve permeability prediction in carbonate reservoirs. SPWLA Annual Logging Symposium, Cartagena - Colombia, June 16-20.

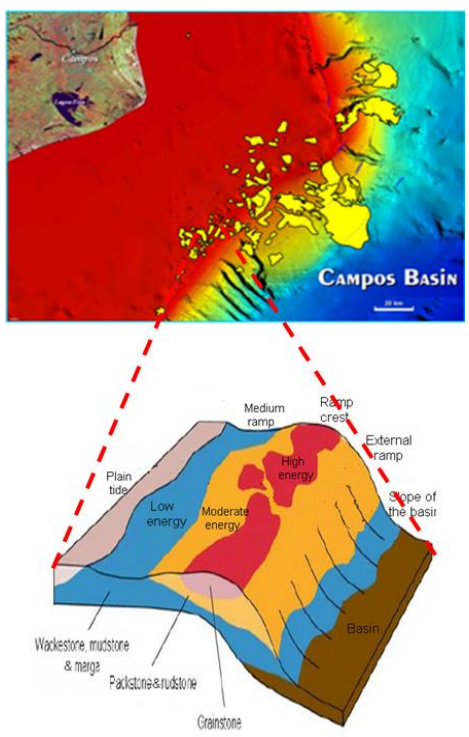

Figura 1. Reservatórios carbonáticos Albianos na Bacia de Campos (modificado de Bruhn et al., 2003). 


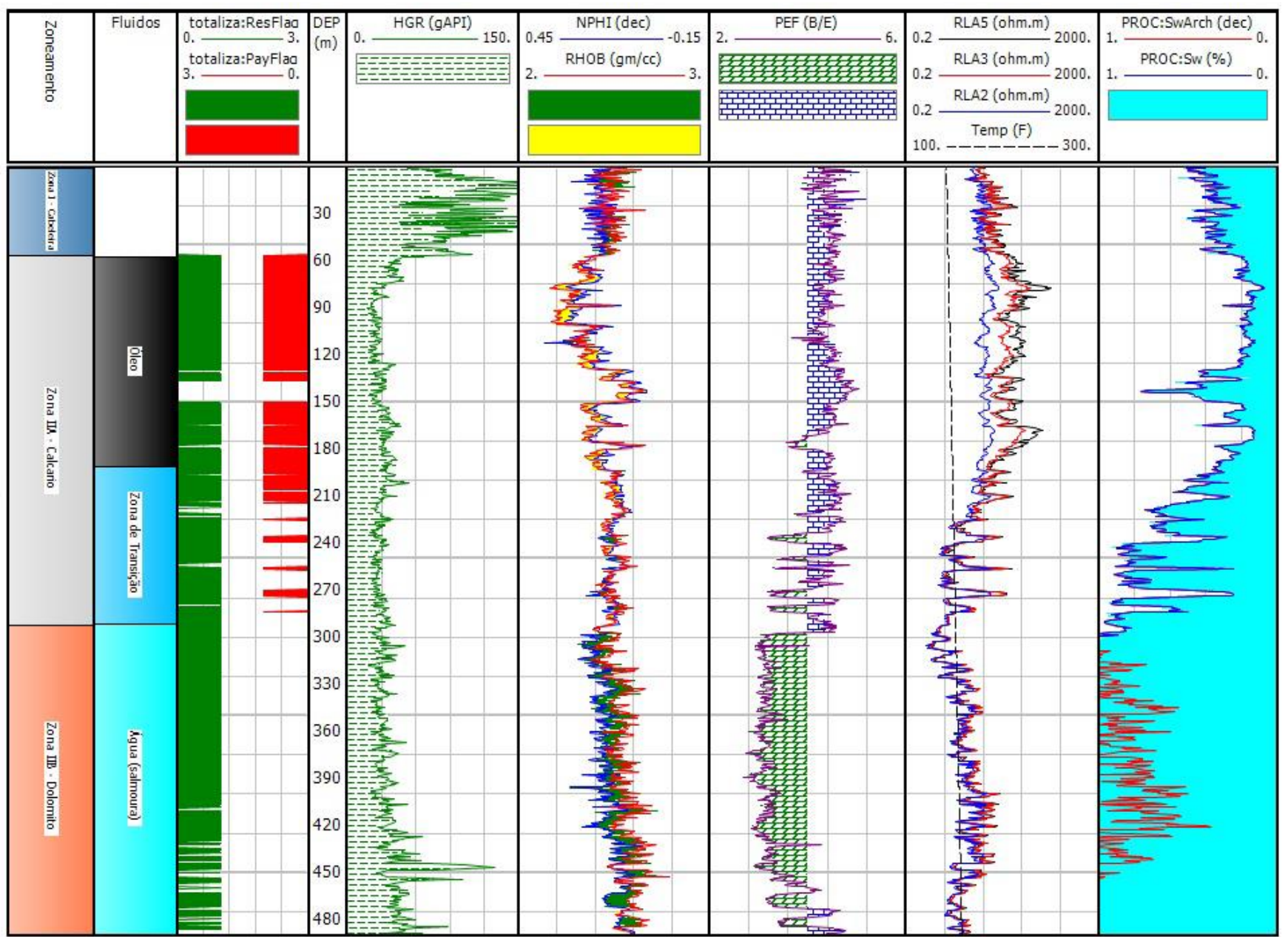

Figura 2. Conjunto de perfis utilizados para zoneamento de litologias, fluidos contidos nos poros rochosos e delimitação do reservatório.
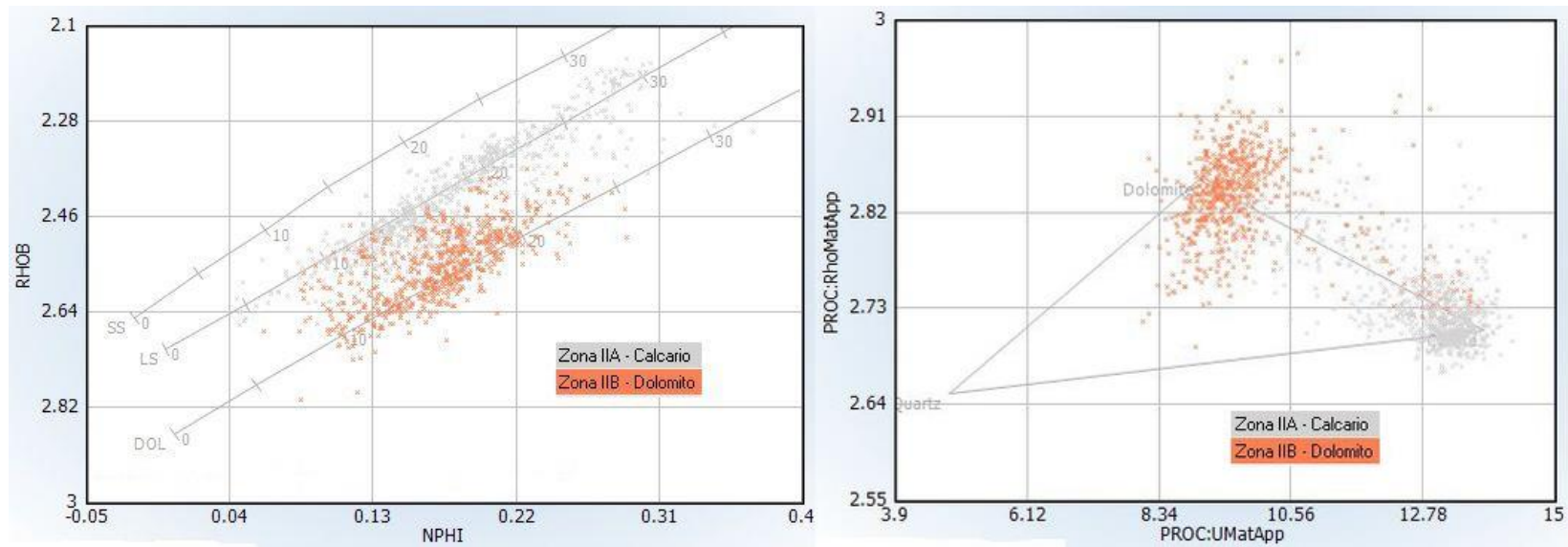

Figura 3. Crossplot entre NPHI e RHOB obtidos pelos perfis (esquerda) e crossplot entre RHOB e absorção fotoelétrica da matriz (direita). 


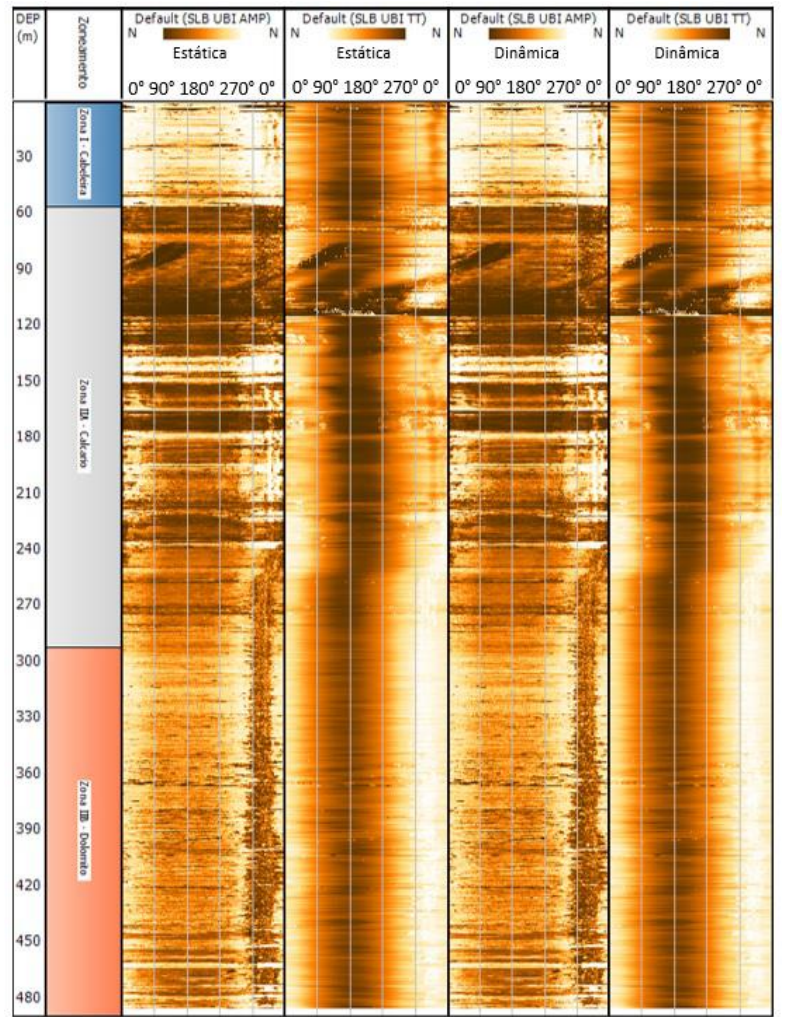

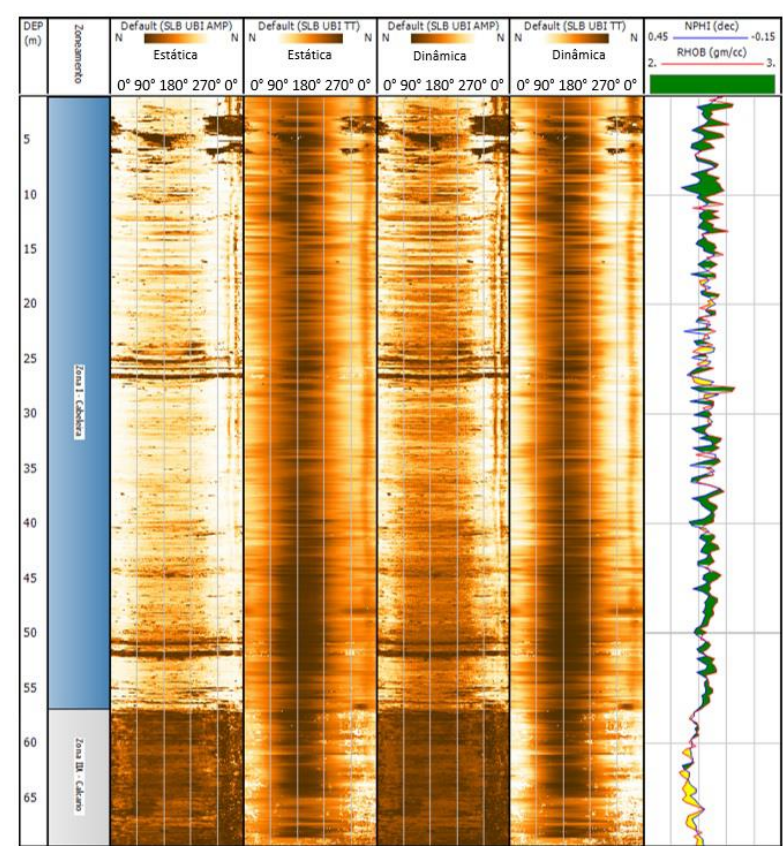

Figura 5. Imagens acústicas da Zona I.

Figura 4. Imagens apresentando todos os 481 metros analisados no Poço X.
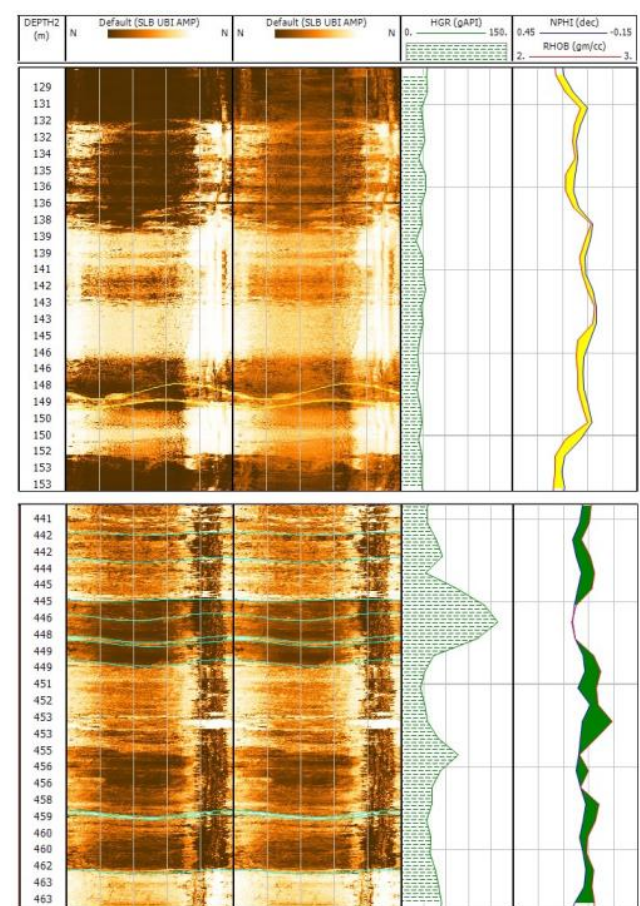

Figura 6. Zona cimentada e intercalação de folheIhos identificadas em duas zonas.

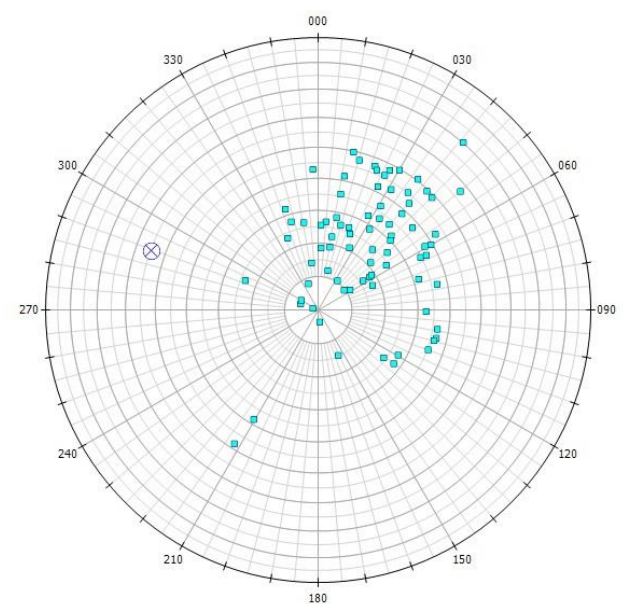

Figura 7. Gráfico estereográfico apresentando a inclinação e orientação dos acamamentos. 

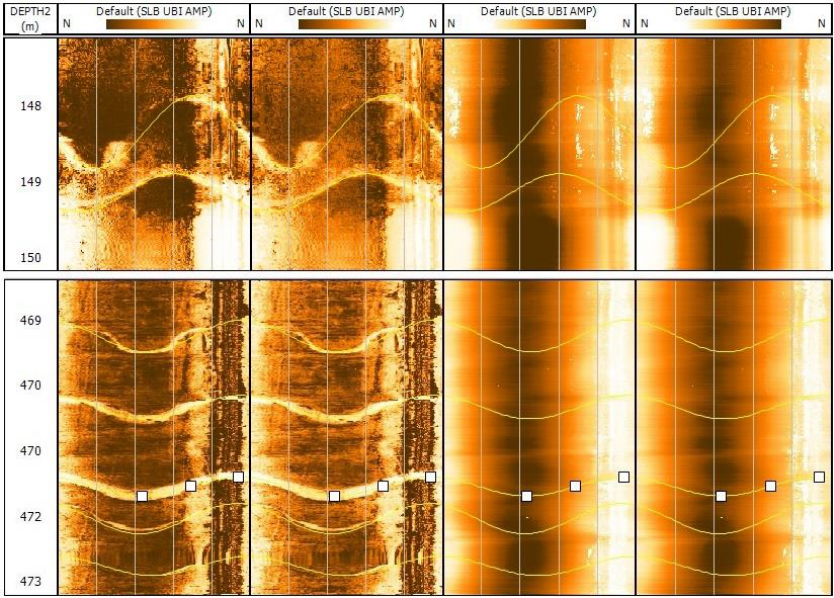

Figura 8. Fraturas naturais preenchidas encontradas no trecho analisado.
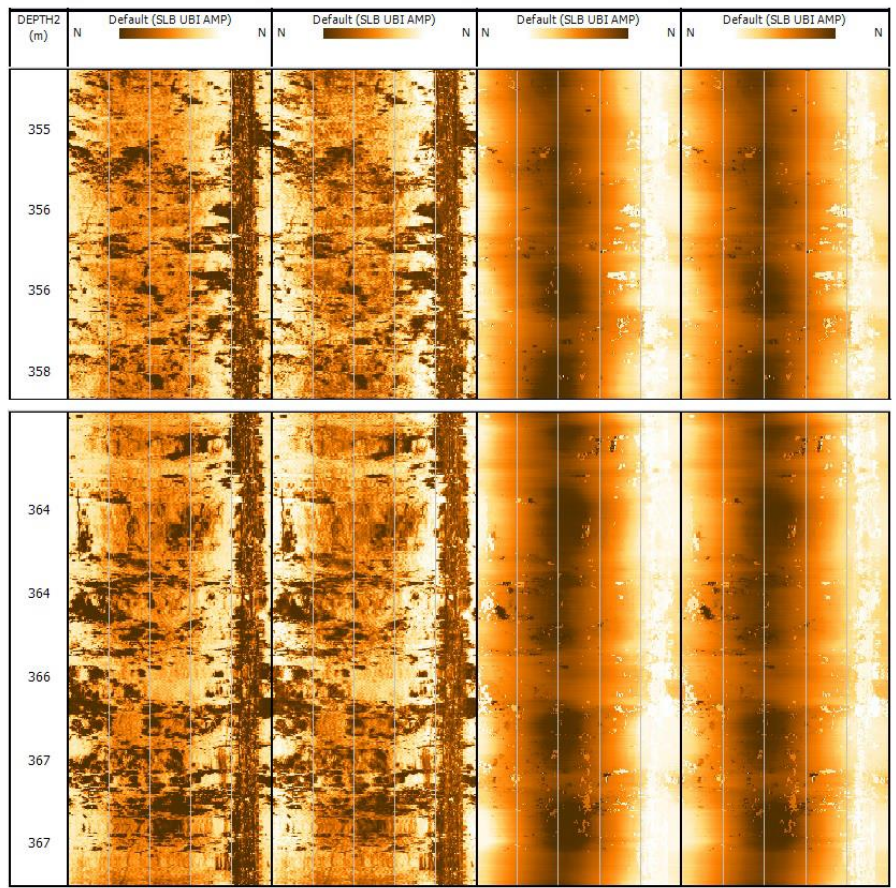

Figura 10. Regiões caracterizadas pela presença de vugs.

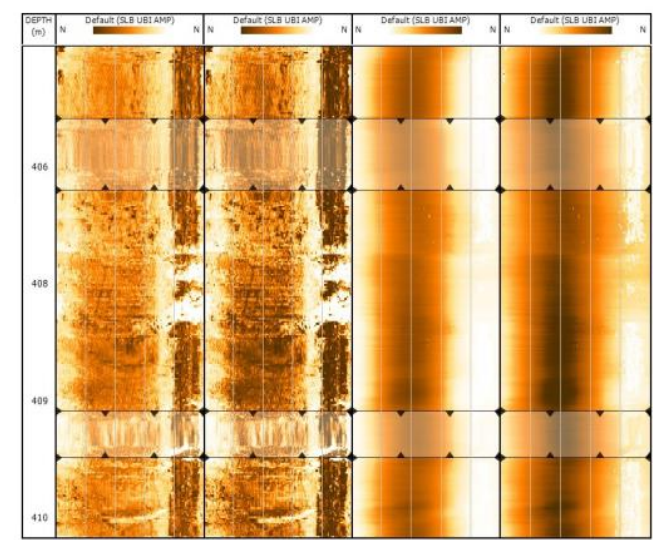

Figura 12. Anomalias registradas nas imagens provocadas pelo aprisionamento da coluna durante a perfilagem.

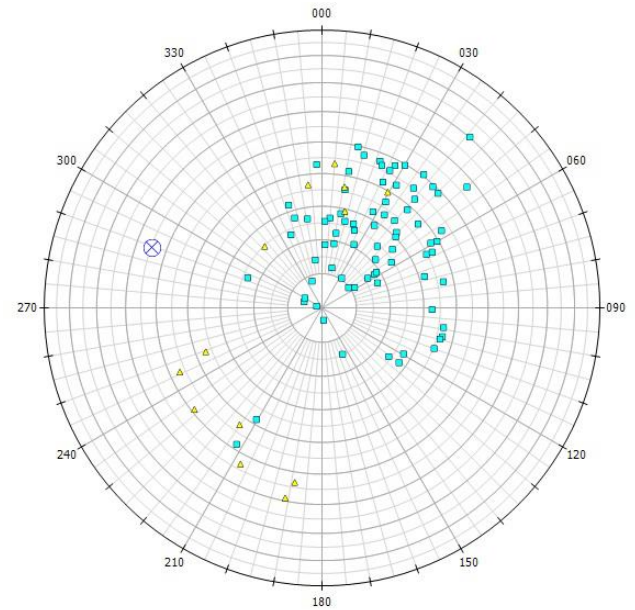

Figura 9. Gráfico estereográfico apresentando a inclinação e orientação das fraturas.

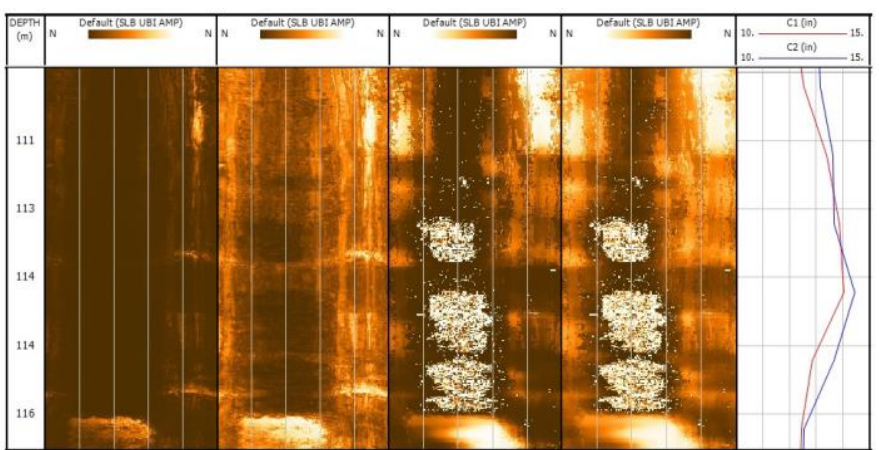

Figura 11. Desmoronamento registrado na profundidade de 111 metros.

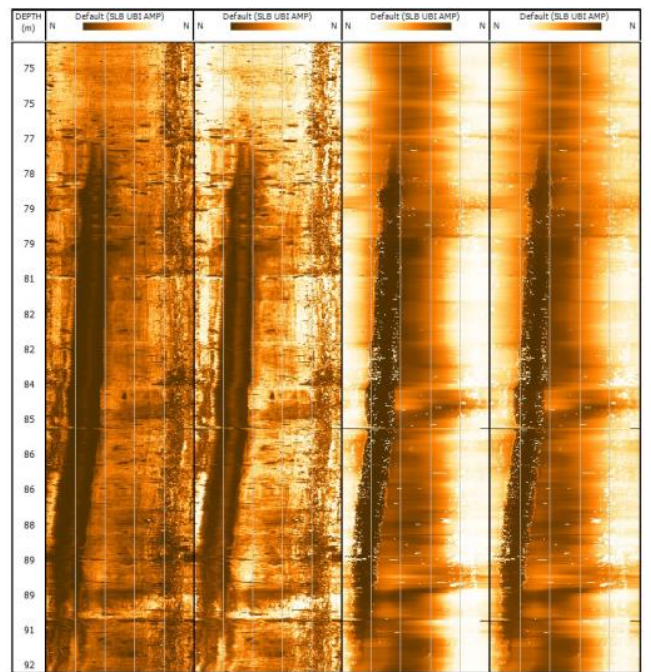

Figura 13. Imagem retrata outro ponto onde a parede do poço foi marcada pela coluna de perfuração. 